\section{Revisiting the Preterm Gastric Aspirate: Potential for Use as an Additional Predictor for Chorioamnionitis, Early-Onset Sepsis, and Complications of Inflammation}

\section{Donna Heicher Conom and Richard J Powers}

Good Samaritan Hospital, San Jose, CA, USA

\begin{abstract}
Objective: To evaluate the potential role of Gastric Aspirate (GA) analysis in diagnosing infection and guiding decisions relating to the use of antibiotics and prevention of complications of prematurity associated with infection.

Methods: This is a prospective observational single-center cohort study of 184 preterm infants less than 33 weeks gestation who underwent GA analysis at birth. It includes a subset of $170(92 \%)$ of these infants whose placentas were examined for Histopathological Chorioamnionitis (HPCA). Comparison of amniocentesis and GA's in a small subset of 6 of these cases was made to confirm that GA was similar to swallowed amniotic fluid.

Results: Gastric aspirates were positive for culture, Gram stain, and/or more than 5 white blood cells per high power field in 59 (32\%) of 184 study infants. Eleven percent (21) had proven (2) or suspected sepsis. A positive "Rapid" GA (RGA) including Gram stain and WBC occurred in $25 \%$. The RGA predicted sepsis or SS with sensitivity $71 \%$, specificity $82 \%$, positive predictive value $33 \%$, negative predictive value $96 \%$, or $11.08(95 \% \mathrm{Cl} 2.46-18.52)$. Full GA including culture predicted the $60(35 \%)$ with HPCA with sensitivity $75 \%$, specificity $91 \%$, positive predictive value $82 \%$, negative predictive value $87 \%$, and OR 30 . Forty-one percent had either HPCA or positive GA or both.

Conclusion: Addition of PH (Placental Histology) and GA to the initial septic work up is beneficial. These added tests provide, with reasonable certainty, identification of the approximately $40 \%$ of preterm infants born prematurely who had intra-uterine infections
\end{abstract}

*Corresponding author: Donna Heicher Conom, Good Samaritan Hospital 2425 Samaritan Drive, San Jose, CA USA 95124, Tel: +1 4083548544; E-mail: conommd@aol.com

Citation: Conom DH, Powers RJ (2015) Revisiting the Preterm Gastric Aspirate: Potential for Use as an Additional Predictor for Chorioamnionitis, Early-Onset Sepsis, and Complications of Inflammation. J Neonatol Clin Pediatr 2: 009.

Received: December 27, 2014; Accepted: January 27, 2015; Published: February 10,2015
GA is helpful in identifying infants who may be septic and need to be treated with antibiotics as well as assisting in the decision to withhold or stop early antibiotics. It also has the potential to help prevent some of the neonatal complications of inflammation.

Keywords: Amniotic Fluid; Chorioamnionitis; Gastrointestinal Contents; Inflammation; Neonate; Preterm Birth; Sepsis

\section{Abbreviations}

BPD: Bronchopulmonary Dysplasia; CBC: Complete Blood Count; CI: Confidence Interval; CRP: C - Reactive Protein; FIR: Fetal Inflammatory Response; GA: Gastric Aspirate; GBS: Group B Strep; HPCA: Histopathological Chorioamnionitis; IVH: Intraventricular Hemorrhage; LR: Bayesian Likelihood Ratio; NEC: Necrotizing Enterocolitis; OR: Odds Ratio; NICU: Neonatal Intensive Care Unit; PCR: Polymerase Chain Reaction; PDA: Patent Ductus Arteriosus; PH: Placental Histology ; PIH: Pregnancy Induced Hypertension; PPHN: Prolonged Pulmonary Hypertension; PROM: Prelabor Rupture of Membranes; PTL: Preterm Labor; PVL: Periventricular Leukomalacia; RGA: Rapid Gastric Aspirate; SS: Suspected Sepsis; WBC/HPF: White Blood Cells per High Power Field

\section{Introduction}

Over the past two decades, there has been a surge of obstetrical interest in Histopathological Chorioamnionitis (HPCA) and related biochemical mechanisms involved in triggering Preterm Labor (PTL) as summarized by Romero et al., [1]. The neonatal literature discusses the involvement of similar biochemical pathways in nearly all the major complications of prematurity. These include developmental delays and cerebral palsy [2-10] related to Periventricular Leukomalacia (PVL) and Intraventricular Hemorrhage (IVH) [11-15], Patent Ductus Arteriosus (PDA) [16,17], Retinopathy of Prematurity (ROP) [18,19], Persistent Pulmonary Hypertension (PPHN) [20], Bronchopulmonary Dysplasia (BPD) [21-30], and Necrotizing Enterocolitis (NEC) [31-34]. It is apparent that HPCA, involving inadequately regulated inflammatory responses influenced by genetic factors $[35,36]$ is frequent and complex while acute treatable early onset neonatal infections such as pneumonia and sepsis are relatively infrequent.

Most HPCA presents insidiously [37-41] and may have various outcomes for the fetus ranging from stillbirth [42] to the "Fetal Inflammatory Response" (FIR) $[1,8,43]$ to immunity against late onset sepsis $[44,45]$. Antibiotics administered to the mother have an uncertain effect on the fetus. They may alter the types of organisms that colonize or infect the premature infant or change the infants' inflammatory responses $[23,46,47]$.

There is serious concern over excessive use of broad spectrum antibiotics in these newborns who receive them without identification of infecting organisms and their microbial sensitivities. Some infants, given the diagnosis of "Suspected Sepsis" (SS) or "culture negative sepsis and pneumonia," receive variable courses of antibiotics, which damage their microbiomes and the surrounding Neonatal Intensive Care Unit (NICU) environment [33,48,49]. 
While the obstetric literature attributes 25 to $40 \%$ [1] of prematurity to infection or inflammation, just 1-2\% [50] of newborns experience blood culture positive early onset sepsis. We theorized that these differing frequencies could be reconciled by expanding the initial sepsis investigation to include more than the currentlyrecommended blood culture with adjunct Complete Blood Counts (CBC's) and serial C - Reactive Protein (CRP) [51,52].

We studied a cohort of preterm infants less than 33 weeks gestation, theorizing that reintroduction of the previously used Gastric Aspirate (GA) examination would: first, correlate favorably with amniocentesis fluid samples performed in a small subset; second, be predictive of early onset infection in the newborn; and third, assist in antibiotic management due to identification of infecting organisms. We also theorized that the GA would correlate with a diagnosis of HPCA and that investigation for infection would benefit from routinely including Placental Histopathogy $(\mathrm{PH})$. In addition, we theorized that, if the GA correlated with HPCA, it has the potential to be useful in earlier identification of infants at higher risk for BPD, PDA, ROP, PPHN, $\mathrm{NEC}, \mathrm{IVH}$ and PVL, at least until routine cytokine measurements become available [53].

\section{Patients and Methods}

We performed a prospective observational cohort study, approved by our Institutional Review Board, analyzing the results of blood cultures, GA, PH, and other maternal and newborn data on all infants admitted to the Neonatal Intensive Care Unit (NICU) who were less than 33 completed weeks gestation at birth. Infants were excluded who did not have a GA performed and those who had lethal congenital anomalies. GA testing had been used routinely by some attending neonatologists prior to the study and had been included in standing admission orders for all infants less than 33 weeks gestation prior to the study. Stomach contents were obtained as soon as possible during stabilization in the delivery room or in the first few hours (always prior to the first feeding) in the NICU, secured in a DeLee trap, and sent to the lab. The Becton Dickinson BACTEC Peds Plus blood culture bottles requiring a minimum of one milliliter of blood were used for infants. BACTEC plus aerobic and Lytic/anaerobic/F bottles were used for mothers. PH exams were done by general pathologists in the hospital laboratory and reported in about 5 days.

The "Rapid" GA (RGA) test was ordered on a STAT basis. It included White Blood Cell count per High Power Field (WBC/HPF) and Gram stain for bacteria or fungi. The full GA included the RGA plus aerobic, anaerobic and Mycoplasma cultures. A positive RGA was defined as positive Gram stain for organisms and/or more than $5 \mathrm{WBC} / \mathrm{HPF}$ similar to amniocentesis counts reported by Romero et al., [54] a positive (full) GA was defined as one or more of the following: positive Gram stain, more than $5 \mathrm{WBC} / \mathrm{HPF}$, or one or more positive cultures. Anaerobic and Mycoplasma cultures were sent to referral labs and results were available after 7 to 9 days. Bacteria considered contaminants were coagulase negative Staph., Proprianobacteria acnes, and any single colonies of non-pathologic organisms. Diphtheroids reported on aerobic culture or Gram stain were considered pathogens because they often grew Gram positive rods on anaerobic culture. No differentiation between heavy and light growth was made. If one of multiples had ruptured membranes, all were included in the Prelabor Rupture of Membranes (PROM) group. Suspected Sepsis (SS) was defined as infants who, at the discretion of the attending physician who evaluated the infants' lab results and length and degree of illness, received a 7 or more day course of antibiotics beginning at birth.
Missing data occurred due to clerical error or inability to obtain a sample. Included infants had, at minimum, aerobic cultures, Gram stain and WBC. Those missing anaerobic cultures and/or cultures for Mycoplasmas were included in the results.

Test versus disease statistical comparisons for sensitivity, specificity, positive and negative predictive values, positive and negative Bayesian likelihood ratios, odds ratios and $\mathrm{P}$ values were calculated to evaluate both the RGA and full GA for prediction of proven or suspected sepsis. In a large subset of study infants who had both GA and PH, calculations for prediction of HPCA were performed. The online calculator www.medcalc.org/calc/diagnostic test.php was used for these calculations.

\section{Results}

A total of 209 newborns less than 33 0/7 weeks gestation were admitted during the study period from December, 2010, through March, 2013. Excluded were three with lethal anomalies and 22 who had no GA performed. Thus, 184 (89\%) of the 206 had at minimum Gram stain, WBC and aerobic cultures, and were included in the study. Table 1 , lists numbers of study infants and excluded infants and the comparative percentages several categories. The excluded group was significantly different only in the percent of patients who died. Thirty-seven (20\%) infants who were missing anaerobic cultures and 30 (16\%) missing Mycoplasma cultures were included in the results. A subset of 170 (92\%) of the 184 infants had PH completed and were included in analysis of the correlations between RGA and GA and PH. Seventy-eight percent of patients were begun on antibiotics after birth. A group of 21 (11\%) with proven or Suspected Sepsis (SS) received 7 or more days of antibiotics. There were 117 males and 67 females in the study.

\begin{tabular}{|c|c|c|c|c|c|}
\hline & \multicolumn{2}{|c|}{ Study patients (184) } & \multicolumn{2}{|c|}{ Excluded (22) } & $P$ value \\
\hline \multicolumn{6}{|l|}{ Birth Weight } \\
\hline $470-1000$ grams & 47 & $25 \%$ & 8 & $36 \%$ & 0.23 \\
\hline $1001-1500$ grams & 62 & $34 \%$ & 6 & $27 \%$ & 0.72 \\
\hline $1501-2000$ grams & 46 & $25 \%$ & 5 & $23 \%$ & 0.92 \\
\hline 2001-2370 grams & 29 & $16 \%$ & 3 & $14 \%$ & 0.93 \\
\hline \multicolumn{6}{|l|}{ Gestational Age } \\
\hline 23-24 weeks & 20 & $11 \%$ & 5 & $23 \%$ & 0.39 \\
\hline 25-26 weeks & 29 & $16 \%$ & 1 & $4 \%$ & 0.74 \\
\hline $27-29$ weeks & 48 & $26 \%$ & 4 & $18 \%$ & 0.72 \\
\hline $30-32$ weeks & 87 & $47 \%$ & 12 & $55 \%$ & 0.58 \\
\hline \multicolumn{6}{|l|}{ Other Categories } \\
\hline Died & 2 & $1 \%$ & 3 & $14 \%$ & $0.02^{*}$ \\
\hline One of Multiples & 55 & $30 \%$ & 6 & $27 \%$ & 0.87 \\
\hline Vaginal delivery & 43 & $23 \%$ & 7 & $32 \%$ & 0.57 \\
\hline C-Section & 141 & $77 \%$ & 15 & $68 \%$ & 0.41 \\
\hline PROM & 71 & $39 \%$ & 10 & $45 \%$ & 0.57 \\
\hline Preterm labor, no PROM & 55 & $30 \%$ & 8 & $36 \%$ & 0.71 \\
\hline
\end{tabular}

Table 1: Study patients divided into categories and compared to the proportion of patients in the same categories who were excluded from the study due to lack of gastric aspirate sample reports.

PROM: Prelabor Rupture of Membranes; * $\mathrm{p}<0.05$

Among 156 mothers in the study, a small subset of 6 underwent amniocentesis to rule out infection prior to delivery of a preterm newborn in whom a GA was done. See results in table 2. The GA 
correlated well with amniocentesis findings in view of the interval time periods during which antibiotics were usually given.

Fifty-nine (32\%) of the 184 study infants had a positive full GA and $25 \%$ had a positive RGA. Table 3 is a listing of positive results for the full and RGA by categories. As we expected, positive full GA increased with decrease in gestational age. The percent with positive
GA in infants born by vaginal deliveries and those with PROM were high as expected. In the 10 study infants born after cervical cerclage, all had at least one positive test when $\mathrm{PH}$ was included. In those 54 (29\%) of the study patients delivered by C/S with no labor and no PROM, only $2(4 \%)$ had a positive GA. The 2 were discordant twins with 7 and $10 \mathrm{WBC} / \mathrm{HPF}$ in their RGA, and negative PH, GA culture, and Gram stain.

\begin{tabular}{|c|c|c|c|c|c|c|c|}
\hline $\begin{array}{l}\text { Case } \\
\text { No. }\end{array}$ & $\begin{array}{l}\text { Gestation in } \\
\text { weeks }\end{array}$ & C-Section Vaginal & Birth Weight & Amniocentesis results & Time Interval & Gastric Result & Placenta \\
\hline 1 & 31 & C-Section & 2110 grams & $\begin{array}{l}9 \text { WBC gluc } 25 \\
\text { rare GBS }\end{array}$ & 1 day & $1 \mathrm{WBC}$ rare GBS & $\begin{array}{l}+ \text { +chorio- } \\
\text {-funitis, hvygm+cocci }\end{array}$ \\
\hline 2 & $286 / 7$ & C-Section & 1000 grams & 2 WBC No growth & $2 \frac{1}{2}$ months & $3-5 \mathrm{WBC}$ & $\begin{array}{l}\text { +chorio } \\
\text { +funisitis, } \\
\text { yellow-green }\end{array}$ \\
\hline 3 & 29 & Vaginal & 1385 grams & $\begin{array}{l}160 \text { WBC Gluc }<20 \\
\text { Heavy GBS }\end{array}$ & $<1$ day & 5-10WBC Light GBS & $\begin{array}{l}\text { +chorio, } \\
\text { +funisitis }\end{array}$ \\
\hline 4 & $284 / 7$ & C-Section & 970 grams & $\begin{array}{l}6 \text { WBC, Gluc }<20 \\
\text { No growth }\end{array}$ & 10 days & Eubacteria, Mycoplasma & $\begin{array}{l}\text { +chorio } \\
\text { +funisitis }\end{array}$ \\
\hline 5 & $275 / 7$ & Vaginal & 1030 grams & 98 WBC Heavy AlphaStrep & $<1$ day & 20-50WBC Heavy Strep Anginosus & $\begin{array}{l}\text { +chorio } \\
\text { +funisitis, } \\
\text { yellow }\end{array}$ \\
\hline 6 & $252 / 7$ & Vaginal & 750 grams & $\begin{array}{l}1000 \text { WBC Ureaplasma } \\
\text { urealyticum }\end{array}$ & 1 day & $\begin{array}{l}100 \text { WBC Moderate } \\
\text { Gm neg rods } \\
\text { No growth }\end{array}$ & $\begin{array}{l}\text { +chorio } \\
\text {-funisitis }\end{array}$ \\
\hline
\end{tabular}

Table 2: Results of a subgroup of 6 amniocenteses done in women in preterm labor compared to the gastric aspirate results of their infants who were in the study born after varying time intervals.

WBC: White Blood Cells per high power field; GBS: Group B Strep; Chorio: Chorioamnionitis; Hvy: Heavy; Gm: Gram; Neg: Negative; Gluc: Glucose

\begin{tabular}{|l|l|l|l|}
\hline Categories & Number Infants & $\begin{array}{l}\text { Positive Gastric } \\
\text { Aspirate (\%) }\end{array}$ & $\begin{array}{l}\text { Positive Rapid Gastric } \\
\text { Aspirate (\%) }\end{array}$ \\
\hline Total infants & 184 & $59(32 \%)$ & $45(25 \%)$ \\
\hline Gestational Age & \multicolumn{3}{|l|}{} \\
\hline 23-24 weeks & 20 & $10(50 \%)$ & $8(40 \%)$ \\
\hline $25-26$ weeks & 29 & $11(38 \%)$ & $6(21 \%)$ \\
\hline $27-29$ weeks & 48 & $15(31 \%)$ & $15(31 \%)$ \\
\hline $30-32$ weeks & 87 & $23(26 \%)$ & $16(18 \%)$ \\
\hline Other Categories & 10 & $7(70 \%)^{*}$ & $4(40 \%)$ \\
\hline Cerclage & 55 & $12(22 \%)$ & $7(13 \%)$ \\
\hline Multiple & 71 & $37(52 \%)$ & $28(39 \%)$ \\
\hline PROM & 55 & $16(29 \%)$ & $12(22 \%)$ \\
\hline PTL-No PROM & 140 & $30(21 \%)$ & $27(19 \%)$ \\
\hline $\begin{array}{l}\text { C-Section } \\
\text { delivery }\end{array}$ & 44 & $29(66 \%)$ & $18(41 \%)$ \\
\hline Vaginal delivery & $44 \%)^{* *}$ & $2(4 \%)$ \\
\hline $\begin{array}{l}\text { No labor, ROM } \\
\text { at C-S }\end{array}$ & 54 & $2(4)$ & \\
\hline
\end{tabular}

See table 4 for calculations of test predictability for disease results including numbers of patients with positive and negative results. Both the RGA and GA proved to correlate well with the group of 21 (11.4\%) with either proven sepsis (2) or SS (19). The RGA is more useful for deciding whether to begin antibiotics after birth because it can easily be reported on a STAT basis. The full GA requires 48 hours for aerobic culture results and 7 to 9 days for Mycoplasma and anaerobic results. It is, thus, more useful for later management of antibiotics after 48 hours. In the subset analysis which included 170 patients who had both PH and GA performed, the full GA was more predictive than the RGA for HPCA with many fewer false negatives.

See table 5 for combined results of tests for the 2 infants with proven sepsis, the 21 infants with sepsis or SS and for those with positive RGA in the 15 infants with and the 30 infants without sepsis or SS. Those with sepsis or SS had very high positive rates of all tests and no negative tests. Those without sepsis or SS also had high rates of positive GA and $\mathrm{PH}$, although not as high as those with sepsis or SS.

Combined PH and GA results from the subset of 170 patients could be divided into 4 groups: see table 6 . Seventy (41\%) had at least one positive test (PH, GA or both) for intrauterine infection. Funisitis was present in 25 (42\%) of those with HPCA and those infants were generally sicker.

Two (1\%) of the 184 study newborns had proven early onset sepsis. Both had positive GA Gram stains. Their GA cultures grew the same organisms as their blood cultures. In the first of the septic infants, the blood culture grew Strep. Pneumonia and his RGA as well as the placenta showed "too numerous to count" WBC's. Delivery of the

Table3: Percent positive (full) gastric aspirates and rapid gastric aspirates in the study by categories.

PROM: Prelabor Rupture of Membranes; PTL: Preterm Labo

*8 $(80 \%)$ had positive $\mathrm{PH}$ and all 10 had at least one + factor, 3 had 2 factors and 3 had 3 . In the one set of twins one had one factor and one had 2 factors but they were the 2 with negative $\mathrm{PH}$.

${ }^{* *}$ Discordant twins with 7 and 10 WBC/HPF, negative GA cultures and Gram stain, and negative $\mathrm{PH}$. 


\begin{tabular}{|l|l|l|l|l|}
\hline & $\begin{array}{l}\text { +RGA/ Sep- } \\
\text { sis or SS }\end{array}$ & +RGA/+PH & $\begin{array}{l}\text { +GA/Sep- } \\
\text { sis or SS }\end{array}$ & +GA/+PH \\
\hline Disease Prevalence & $11.41 \%$ & $35.29 \%$ & $11.41 \%$ & $35.29 \%$ \\
\hline $\begin{array}{l}\text { \#Patients + for } \\
\text { disease }\end{array}$ & 21 & 60 & 21 & 60 \\
\hline \#Patients tested & & & & \\
\hline Total number & 184 & 170 & 184 & 170 \\
\hline a (true+) & 15 & 27 & 18 & 45 \\
\hline b (false+) & 30 & 7 & 41 & 10 \\
\hline c (false neg) & 6 & 33 & 3 & 15 \\
\hline d (true neg) & 133 & 103 & 122 & 100 \\
\hline a + b (total+) & 45 & 34 & 59 & 55 \\
\hline c + d (total neg) & 139 & 136 & 125 & 115 \\
\hline \% Sensitivity & 71.43 & 45.00 & 85.71 & 75.00 \\
\hline $95 \%$ Cl & $47.83-88.65$ & $32.13-58.39$ & $63.63-96.78$ & $2.14-85.27$ \\
\hline \% Specificity & 81.60 & 93.64 & 74.85 & 90.91 \\
\hline $95 \%$ Cl & $74.78-87.22$ & $87.32-97.39$ & $67.46-81.30$ & $83.91-95.55$ \\
\hline+ Likelihood Ratio & 3.88 & 7.07 & 3.41 & 8.25 \\
\hline $95 \%$ Cl & $2.55-5.92$ & $3.28-15.27$ & $2.48-4.68$ & $4.49-15.16$ \\
\hline Neg Likelihood Ratio & 0.35 & 0.59 & 0.19 & 0.28 \\
\hline $95 \%$ Cl & $0.18-0.69$ & $0.46-0.74$ & $0.07-0.55$ & $0.18-0.43$ \\
\hline \% + Predictive Value & 33.33 & 79.41 & 30.51 & 81.82 \\
\hline $95 \%$ Cl & $20.01-48.95$ & $62.09-91.26$ & $19.19-43.87$ & $69.09-90.91$ \\
\hline \% Neg Predictive & 95.68 & 75.74 & 97.60 & 86.96 \\
\hline Value & $90.84-98.39$ & $67.64-82.67$ & $93.14-99.47$ & $79.40-92.51$ \\
\hline $95 \%$ Cl & 11.08 & 12.03 & 17.85 & 30.00 \\
\hline Odds Ratio & $3.97-30.93$ & $4.80-30.18$ & $5.00-63.73$ & $12.51-71.90$ \\
\hline $95 \%$ Cl & $<0.0001$ & $<0.0001$ & $<0.0001$ & $<0.0001$ \\
\hline P value & & & & \\
\hline & & & & \\
\hline
\end{tabular}

Table 4: Test/disease predictability correlations for +RGA and + (full) GA versus + for Sepsis or Suspected Sepsis and +PH.

SS: Suspected Sepsis; PH: Placental Histology

\begin{tabular}{|l|l|l|l|l|l|l|}
\hline & $\begin{array}{l}\text { \# Pa- } \\
\text { tients }\end{array}$ & +RGA & +GA culture & +PH & All +All & Neg \\
\hline $\begin{array}{l}\text { +Sepsis, } \\
\text { proven }\end{array}$ & 2 & 2 & 2 & 1 & 1 & 0 \\
\hline $\begin{array}{l}\text { +Sepsis } \\
\text { or SS }\end{array}$ & 21 & $\begin{array}{l}15 / 21 \\
(71 \%)\end{array}$ & $19 / 21(90 \%)$ & $17 / 20(85 \%)$ & $12 / 21(57 \%)$ & 0 \\
\hline $\begin{array}{l}\text { +RGA, } \\
\text { not septic } \\
\text { or SS }\end{array}$ & 30 & - & $20 / 30(67 \%)$ & $20 / 30(67 \%)$ & $15 / 30(50 \%)$ & $\begin{array}{l}6 \\
(20 \%)\end{array}$ \\
\hline $\begin{array}{l}\text { +RGA/ } \\
\text { +septic or } \\
\text { SS }\end{array}$ & 15 & - & $15 / 15(100 \%)$ & $12 / 14(86 \%)$ & $12 / 14(86 \%)$ & 0 \\
\hline
\end{tabular}

Table 5: Test results for patients with proven sepsis, proven or suspected sepsis, and + RGA with and without sepsis or suspected sepsis.

second septic baby was induced for Pregnancy Induced Hypertension (PIH) after artificial PROM. Blood and GA grew both E. Coli and Group B Strep (GBS). Polymicrobial sepsis cases such as this have been documented [55,56]. GA Gram stain showed organisms but no WBC's.

Another case of interest was an infant whose mother had a positive anaerobic blood culture for Prevotella. The infant was one of 26 week twins with PROM for 9 weeks who developed septic shock after C-section. Twin A's GA showed more than $100 \mathrm{WBC} / \mathrm{HPF}$, heavy

\begin{tabular}{|c|l|l|}
\hline & + GA & -GA \\
\hline$+P H$ & $\begin{array}{l}45(26 \%) \\
\text { Acute infection.WBC, bacteria or both. }\end{array}$ & $\begin{array}{l}15(9 \%) \\
\text { Past or cured infection or poor } \\
\text { swallowing. }\end{array}$ \\
\hline -PH & $\begin{array}{l}10(6 \%) \\
\text { Acute but too early for WBC response }\end{array}$ & $\begin{array}{l}100(59 \%) \\
\text { No apparent infection }\end{array}$ \\
\hline
\end{tabular}

Table 6: Numbers of patients in 4 groups with combinations of $+/-\mathrm{PH}$ and $+/-\mathrm{GA}$ Gram negative coccobacilli on gram stain, and grew Prevotella. She required inhaled nitric oxide and ventilation. Twin $\mathrm{B}$ had a negative GA and benign course. $\mathrm{PH}$ was negative.

Forty-nine $(27 \%)$ of the 184 study infants had one or more positive cultures of the GA. Table 7 lists the organisms by categories. There were 15 cultures omitted as contaminants. Each positive culture grew 1 to 3 organisms. There were 27 with one, 21 with two and one with three organisms. There were 46 aerobic organisms cultured and $24(34 \%)$ anaerobic organisms. The most common organism, found in 11 infants, was Ureaplasma urealyticum. The organisms found in the study GA's are similar to organisms found in amniotic fluid from amniocentesis from women in PTL with intact membranes [37,38,40,57-60]. All four infants noted to be foul-smelling grew anaerobes.

Due to concern over possible contamination of the GA in the vaginal deliveries, we looked at other factors in those $26 / 43$ (60\%) who had positive GA cultures. Half of these had both positive placentas and WBC's, most more than 20/HPF. The others had at least one other factor including positive placenta, positive WBC, foul smell, and twins who grew the same organisms in both of their GA's and had high CRP's. Thus in none of these positives was the GA the only factor consistent with infection.

\section{Discussion}

Historically, discovery of a rapid test to diagnose early onset neonatal sepsis while we await the "gold standard" blood culture result has eluded us [61-63]. This has resulted in extreme caution to avoid missing infants whose blood cultures eventually prove positive or falsely negative. During the two decades prior to 1996, when prophylactic antibiotics during labor were begun for GBS colonization, fulminant early-onset GBS sepsis was seen much more frequently than it is now [64]. During that time, the GA was commonly used to screen for GBS sepsis and pneumonia. It was known that gastric acid was not present in the newborn's stomach until after the first feeding [65]. Seeing Gram positive cocci with or without WBC's in the GA was used to decide whether a baby should receive ampicillin, without the delay of awaiting CBC's or improvement in transient respiratory distress [66]. Some of those with a negative GA could be left off antibiotics to see if they improved. The GA as a reflection of swallowed lung organisms in non-ventilated babies was also considered useful, as was the GA culture confirming GBS when an infant had blood culture negative pneumonia $[67,68]$. Although GBS remains a fulminant, although less frequent, cause of sepsis [55], the GA Gram stain and culture have fallen out of favor $[69,70]$, being considered of no value by some [71]. Rather, the focus is now on developing a highly technical method of testing for infection in the amniotic fluid and gastric aspirates, the 16s rDNA PCR (PCR). Two such recent studies of PCR's done on GA's prompted our desire to re-examine the usefulness of GA sampling $[72,73]$. Although the development of a rapid PCR would be beneficial, much study will be needed before the meaning of results in newborns can be fully understood and readily available. 


\begin{tabular}{|c|c|}
\hline Organism & Number of Infants with + cultures \\
\hline \multicolumn{2}{|l|}{ Mycoplasmas } \\
\hline Ureaplasma urealyticum & 11 \\
\hline Mycoplasma hominis & 3 \\
\hline \multicolumn{2}{|l|}{ Fungi } \\
\hline Candida & 3 \\
\hline \multicolumn{2}{|l|}{ Aerobic bacteria } \\
\hline \multicolumn{2}{|l|}{ Aerobic gram positive cocci } \\
\hline Alpha Strep & 8 \\
\hline Strep.mitis & 1 \\
\hline Strep.anginosus & 2 \\
\hline Strep.agalactiea (GBS) & 7 \\
\hline Non-hemolytic Strep. & 2 \\
\hline Strep.pneumoniae (Pneumococcus) & 1 \\
\hline Enterococcus & 1 \\
\hline $\begin{array}{l}\text { Staph.aureus (mom had purulent } \\
\text { salpingitis) }\end{array}$ & 1 \\
\hline \multicolumn{2}{|l|}{ Aerobic Gram negative rods } \\
\hline E. coli & 5 \\
\hline Morganella morganii (facultative) & 3 \\
\hline \multicolumn{2}{|l|}{ Aerobic Gram positive rods } \\
\hline Gardenerella & 1 \\
\hline \multicolumn{2}{|l|}{ Anaerobic bacteria } \\
\hline \multicolumn{2}{|l|}{ Anaerobic Gram positive cocci } \\
\hline Peptostreptococcus & 8 \\
\hline \multicolumn{2}{|l|}{ Anaerobic Gram positive rods } \\
\hline Clostridium & 3 \\
\hline Eubacteria & 1 \\
\hline \multicolumn{2}{|l|}{ Anaerobic Gram negative rods } \\
\hline Prevotella & 5 \\
\hline Fusobacterium & 3 \\
\hline Bacteroides & 2 \\
\hline Campnocytophagia (facultative) & 1 \\
\hline Eikenella corrodes (facultative) & 1 \\
\hline
\end{tabular}

Table 7: Classification of organisms and number of infants with positive gastric aspirate cultures.

Currently, determining which babies are actively infected and may benefit from antibiotics remains dependent on blood cultures, degree of illness, and adjunct lab results [61]. The results of our study seem to justify considering reinstitution the GA as an adjunct laboratory test in the initial newborn septic work up. Although the positive predictive value of RGA is only $33 \%$, this correlation is similar to the positive predictive findings in Benitz' 1998 statistical analysis of the use of early and serial CRP testing for diagnosing of sepsis [74]. In spite of that, the CRP is now used routinely because the positive predictive values are still higher than the relatively low incidence of sepsis.

The most urgently sought objective of studies investigating laboratory tests for infection is to identify methods to decrease both the routine initiation and prolonged administration of broad spectrum antibiotics [75,76]. Antibiotics were started at birth in $78 \%$ of the infants in our study. This large number is similar to other recent studies, including the one by Stoll et al., in 2011 [55], in which $82 \%$ of ELBW infants were treated. More timely than the CRP, which is usually done only after 12 hours of age, the RGA potentially improves our ability to narrow down the numbers of infants initially given antibiotics from the current about $80 \%$ to closer to $30-40 \%$. While the RGA's positive predictive value of $33 \%$ means we will treat 3 times the $11 \%$ at risk, that would be an improvement over treating $80 \%$, more than 7 times too many. The negative predictive value of the RGA is $96 \%$, which likely further supports the decision not to treat in many patients. Certainly, there are some with false negatives, likely those in high risk groups and who have clinical signs and symptoms at birth, who will need to be treated initially. Subsequently, a negative full GA with aerobic culture results and a negative predictive value of $98 \%$ can be used in the decision along with negative or equivocal CBC and CRP to stop antibiotics. This will likely bring down the numbers of those treated for a lengthy course. Infants with a positive full GA alone must not be automatically treated, but again evaluated along with other adjunct tests. If their other adjunct tests are negative, they likely have intra-uterine infection without neonatal infection. The $29 \%$ of study infants in our low risk category of C/S, no PROM and no labor, and negative $\mathrm{PH}, 96 \%$ of whom have negative RGA, will need antibiotics at birth very rarely. A larger study using the GA, which includes more infants with proven sepsis, would likely provide a more exact number of infants who could reasonably be spared early antibiotic courses.

Our findings of 4 groups of GA and $\mathrm{PH}$ seem to support the idea of a somewhat complex continuum of HPCA and/or intra-uterine infection with variable implications in individual patients, a concept also requiring further investigation. It appears that, in the $41 \%$ with either a positive GA, $\mathrm{PH}$ or both, infection has likely triggered the cascade leading to PTL. We speculate, as in table 6, as follows: In Group 1(26\%) with both GA and PH positive, there is likely an active, acute process. This infants' GA may show either a good WBC response or bacteria or both. In Group 2 (9\%) with positive PH and ("false") negative GA, a sub-acute or resolved process may have occurred due to antibiotics or an effective maternal immune response. This may still eventually result in preterm delivery as in our amniocentesis case number two. Those in this group may do well in the NICU or they might have unexpected PVL on an early head ultrasound with later cerebral palsy. In Group 3 (6\%) with ("false") positive GA and negative $\mathrm{PH}$, there is likely a rapidly progressive acute intra-uterine infection which lacks the time for mother or infant to produce a robust WBC response before delivery. This group would seem to have the potential to be sicker as in our second septic infant, and also, perhaps, more likely to have an ascending infection beginning after PROM. In Group $4(59 \%)$ there is no evidence of infection.

Obtaining a GA also aids patient management by identifying specific bacterial pathogens in sick infants. As seen in table 7, there are multiple species of pathogens that may be present for any one morphologic Gram stain result. Knowing results of the early Gram stain from the RGA, when positive in a sick infant, has potential to greatly improve early antibiotic management. Although, ampicillin and gentamicin are the broad spectrum antibiotics of choice, resistance to ampicillin is increasing [77,78] and gentamicin sometimes does not penetrate well into the lungs and spinal fluid [79]. The RGA result can improve antibiotic management, for example, when the Gram stain shows a Gram negative rod. If the Gram negative rod is found in the GA of a foul-smelling infant who doesn't respond to the routine antibiotics, it may be a resistant anaerobe and require coverage with meropenem or metronidazole. If the infant who is not responding to antibiotics is not foul-smelling, the infection may be caused by a resistant aerobe which would respond better to Cefotaxime. Occasionally Gram positive cocci are eventually 
identified as a resistant Staph. aureus or Strep. mitis which would also respond better to a change in antibiotic coverage.

Further potential use for the RGA occurs early when high numbers of WBC's are reported, likely indicating significant inflammation. Also, since positive GA correlates well with HPCA, we can use the GA to help diagnose placental inflammation. Although our study was not large enough to investigate this, the literature indicates that inflammation or HPCA results in an increased incidence of CLD, PDA, PPHN, ROP, and NEC. Thus, in cases of inflammatory WBC response in RGA, PH or both, we speculate that these patients can be designated as high risk and in need of particular emphasis on prevention of these debilitating diseases. Preventive measures include, for example, earlier trials of extubation to prevent BPD, increased attention to avoiding hypoxia and excessive oxygen saturation swings to prevent PPHN and ROP, and exclusive use of breast milk feeding to prevent NEC.

A higher number of polymicrobial and anaerobic cultures than expected was found in our study. There is evidence that anaerobes found in periodontal disease may be seeded hematologically to the amniotic cavity [80]. In particular, Bearfield [81] found that Fusobacterium, Eikenella corrodes, Campnocytophagia, Eubacteria, Peptostreptococcus and Prevotella, all grown in our study, are found in the oral cavity from an early age. She concluded that they carry a high probability of a non-genitourinary and non-gastrointestinal source when found in amniotic fluid. In addition, Aagaard [82] has also more recently found, by studying $16 \mathrm{~S}$ ribosomal DNA, that the aggregate placental microbiome is most akin to the human oral microbiome. In her study, there were also associations with a remote history of antenatal infection, such as urinary tract infections in the first trimester, as well as with preterm birth. Our study and Dr. Aagaard's call attention to the possibility that improving maternal dental health may be more important in prematurity prevention than we have previously thought.

The fact that we can predict HPCA with the GA has an additional potential for use, along with $\mathrm{PH}$ when available, in the medico-legal defense of obstetrical and neonatal cases of unexpected cerebral palsy. Children with positive GA have evidence of risk for FIR in-utero, therefore increasing the chances that the central nervous system insult, most often due to PVL, occurred prior to PTL.

The limitations of our study include the unlikely possibility of false positives in vaginal deliveries, false negatives due to fastidious organisms and viruses (especially cytomegalovirus), antibiotics, and occasional problems obtaining samples. Treatment with prolonged antibiotics in some of the 19 infants with SS may have been influenced by knowledge of results of GA rather than other infant adjunct labs alone, although the number getting long antibiotic courses in the study was relatively few. In addition, some babies may have been too sick in utero to swallow amniotic fluid. In some with oligo hydramnios and/or PROM, there may not have been enough fluid to swallow. Inability to produce an acute WBC response in the face of overwhelming infection may have resulted in low or negative GA WBC counts. Inclusion of patients missing anaerobic and Mycoplasma cultures likely means that several positives were missed. We also know that the majority of bacteria in the human microbiome are too fastidious to grow in currently available culture media $[1,83]$.

\section{Conclusion}

Expansion of the early-onset sepsis evaluation at birth by addition of the GA (with anaerobic and Mycoplasma cultures), and PH to the routine blood culture, CBC's and CRP's can provide important useful information. Judicious interpretation of the easily available GA test done after birth, when added to degree of clinical illness, $\mathrm{PH}$, blood culture, $\mathrm{CBC}$ and $\mathrm{CRP}$ has the potential to significantly improve the understanding and treatment of infection in preterm infants. Larger studies involving more infants with proven sepsis in infants of all gestational ages are needed. Development of micro-methods to culture blood for anaerobic sepsis and rapid screening for Mycoplasmas are also needed to aid in decreasing the needless use of broad spectrum antibiotics.

\section{Acknowledgements}

Thanks to the following who supported this study: Dr. William Benitz, Lucille Packard Children's Hospital, Dr. Andrew Combs, Obstetrix Medical Group, Dr. Robert Armstrong, Valley Infectious Disease Associates, the neonatologists and neonatal nurse practitioners of the Pediatrix Medical Group, Dr. Bruce Douglas and Shanta Day, M.T. (ASCP), and Mike Liddicoat, M.A., M.L.I.S.

\section{References}

1. Romero R, Espinoza J, Kusanovic JP, Gotsch F, Hassan S, et al. (2006) The preterm parturition syndrome. BJOG 113: 17-42.

2. O'Shea TM, Allred EN, Kuban KCK, Epidem SM, Dammann O, et al. (2012) Elevated concentrations of inflammation-related proteins in postnatal blood predict severe developmental delay at 2 years of age in extremely preterm infants. J Pediatr 160: 395-401.

3. Carlo WA, McDonald SA, Tyson JE, Stoll BJ, Ehrenkranz RA, et al. (2011) Cytokines and neurodevelopmental outcomes in extremely low birth weight infants. J Pediatr 159: 919-925.

4. Shah DK, Doyle LW, Anderson PJ, Bear M, Daley AJ, et al. (2008) Adverse neurodevelopment in preterm infants with postnatal sepsis or necrotizing enterocolitis is mediated by white matter abnormalities on magnetic resonance imaging at term. J Pediatr 153: 170-175.

5. Neufeld MD, Frigon C, Graham AS, Mueller BA (2005) Maternal infection and risk of cerebral palsy in term and preterm infants. J Perinatol 25: 108-113.

6. Stoll BJ, Hansen NI, Adams-Chapman I, Fanaroff AA, Hintz SR, et al. (2004) Neurodevelopmental and growth impairment among extremely low-birthweight infants with neonatal infection. JAMA 292: 2357-2365.

7. Wu YW, Escobar GJ, Grether JK, Croen LA, Greene JD, et al. (2003) Chorioamnionitis and cerebral palsy in term and near-term infants. JAMA 290: 2677-2684

8. Yoon BH, Romero R, Park JS, Kim CJ, Kim SH, et al. (2000) Fetal exposure to an intra-amniotic inflammation and the development of cerebral palsy at the age of three years. Am J Obstet Gynecol 182: 675-681.

9. Redline RW, Wilson-Costello D, Borawski E, Fanaroff AA, Hack M (2000) The relationship between placental and other perinatal risk factors for neurologic impairment in very low birth weight children. Pediatr Res 47: 721-726.

10. Wu YW, Colford JM Jr (2000) Chorioamnionitis as a risk factor for cerebral palsy: A meta-analysis. JAMA 284: 1417-1424.

11. Vergani $P$, Patanè L, Doria $P$, Borroni $C$, Cappellini $A$, et al. (2000) Risk factors for neonatal intraventricular haemorrhage in spontaneous prematurity at 32 weeks gestation or less. Placenta 21: 402-407.

12. Vergani P, Locatelli A, Doria V, Assi F, Paterlini G, et al. (2004) Intraventricular hemorrhage and periventricular leukomalacia in preterm infants. Obstet Gynecol 104: 225-231. 
13. Perlman JM, Risser R, Broyles RS (1996) Bilateral cystic periventricular leukomalacia in the premature infant: associated risk factors. Pediatrics 97 822-827.

14. Dammann O, Leviton A (1997) Maternal intrauterine infection, cytokines, and brain damage in the preterm newborn. Pediatr Res 42: 1-8.

15. Verma U, Tejani N, Klein S, Reale MR, Beneck D, et al. (1997) Obstetric antecedents of intraventricular hemorrhage and periventricular leukomalacia in the low-birth-weight neonate. Am J Obstet Gynecol 176: 275-281.

16. Kim ES, Kim E, Choi CW, Kim H, Kim B, et al. (2010) Intrauterine inflammation as a risk factor for persistent ductus arteriosus patency after cyclooxygenase inhibition in extremely low birth weight infants. J Pediatr157: 745-750.

17. Bancalari E, Claure N, Gonzalez A (2005) Patent ductus arteriosus and respiratory outcome in premature infants. Biol Neonate 88: 192-201.

18. Tremblay S, Favret S, Binet F, Chaychi S, Polosa A, et al.(2013) Systemic post-natal inflammatory stress provokes severe abnormalities in developmental retinal angiogenesis and leads to deficits in retinal function. Annual Meeting of the Pediatric Academic Societies, Washington DC, USA

19. Polam S, Koons A, Anwar M, Shen-Schwarz S, Hegyi T (2005) Effect of chorioamnionitis on neurodevelopmental outcome in preterm infants. Arch Pediatr Adolesc Med 159: 1032-1035.

20. Aikio O, Metsola J, Vuolteenaho R, Perhomaa M, Hallman M (2012) Transient defect in nitric oxide generation after rupture of fetal membranes and responsiveness to inhaled nitric oxide in very preterm infants with hypoxic respiratory failure. J Pediatr161: 397-403.

21. Schneibel KR, Fitzpatrick AM, Ping XD, Brown LA, Gauthier TW (2013) Inflammatory mediator patterns in tracheal aspirate and their association with bronchopulmonary dysplasia in very low birth weight neonates. J Perinato 33: 383-387.

22. Plakkal N, Soraisham AS, Trevenen C, Freiheit EA, Sauve R (2013) Histological chorioamnionitis and bronchopulmonary dysplasia: a retrospective cohort study. J Perinatol 33: 441-445.

23. Wright CJ, Kirpalani $H$ (2011) Targeting inflammation to prevent bronchopulmonary dysplasia: can new insights be translated into therapies? Pediatrics 128: $111-126$.

24. Been JV, Rours IG, Kornelisse RF, Jonkers F, de Krijger RR, et al. (2010) Chorioamnionitis alters the response to surfactant in preterm infants. J Pediatr 156: 10-15

25. Bohrer B, Silveira RC, Neto EC, Procianoy RS (2010) Mechanical ventilation of newborns infant changes in plasma pro- and anti-inflammatory cytokines. J Pediatr 156: 16-19

26. Lahra MM, Beeby PJ, Jeffery HE (2009) Intrauterine inflammation, neonatal sepsis, and chronic lung disease: a 13-year hospital cohort study. Pediatrics 123: $1314-1319$.

27. Ambalavanan N, Carlo WA, D'Angio CT, McDonald SA, Das A, et al. (2009) Cytokines associated with bronchopulmonary dysplasia or death in extremely low birth weight infants. Pediatrics 123: 1132-1141.

28. Jobe $\mathrm{AH}$ (2005) Antenatal associations with lung maturation and infection. $J$ Perinatol 2: 31-35.

29. Van Marter LJ, Dammann O, Allred EN, Leviton A, Pagano M, et al. (2002) Chorioamnionitis, mechanical ventilation, and postnatal sepsis as modulators of chronic lung disease in preterm infants. J Pediatr 140: 171-176.

30. Watterberg KL, Demers LM, Scott SM, Murphy S (1996) Chorioamnionitis and early lung inflammation in infants in whom bronchopulmonary dysplasia develops. Pediatrics 97: 210-215.

31. Been JV, Lievense S, Zimmermann LJ, Kramer BW, Wolfs TG (2013) Chorioamnionitis as a risk factor for necrotizing enterocolitis: a systematic review and meta-analysis. J Pediatr 162: 236-242.

32. Morowitz MJ, Poroyko V, Caplan M, Alverdy J, Liu DC (2010) Redefining the role of intestinal microbes in the pathogenesis of necrotizing enterocolitis. Pediatrics 125: 777-785.
33. Cotten CM, Taylor S, Stoll B, Goldberg RN, Sanchez PJ, et al.(2009) Prolonged duration of initial empirical antibiotic treatment is associated with increased rates of necrotizing enterocolitis and death for extremely low birth weight infants. Pediatrics 123: 58-66.

34. Alexander VN, Northrup V, Bizzarro MJ (2011) Antibiotic exposure in the newborn intensive care unit and the risk of necrotizing enterocolitis. J Pediatr 159: $392-397$

35. Sampath V, Mulrooney NP, Garland JS, He J, Patel AL, et al. (2013) Toll-like receptor SNP's modulate sepsis risk and wbc counts in vlbw infants. Proceedings of the Annual Meeting of Pediatric Academic Societies, Washington DC, USA.

36. Reiman M, Kujari H, Ekholm E, Lapinleimu H, Lehtonen L, et al. (2008) Interleukin-6 polymorphism is associated with chorioamnionitis and neonatal infections in preterm infants. J Pediatr 153: 19-24

37. Combs CA, Hickok D, Garite T, Porreco R, Hollemon D, et al. (2009) Intraamniotic infection not reliably predicted by clinical signs and symptoms. Am J Obstetr Gynecol 201: 168-169.

38. Watts DH, Krohn MA, Hillier SL, Eschenbach DA (1992) The association of occult amniotic fluid infection with gestational age and neonatal outcome among women in preterm labor. Obstet Gynecol 79: 351-357.

39. Kim SM, Romero R, Lee J, Lee SM, Park CW, et al. (2012) The frequency and clinical significance of intra-amniotic inflammation in women with preterm uterine contractility but without cervical change: do the diagnostic criteria for preterm labor need to be changed? J Matern Fetal Neonatal Med 25: 1212 1221.

40. Hitti J, Tarczy-Hornoch P, Murphy J, Hillier SL, Aura J, et al. (2001) Amniotic fluid infection, cytokines, and adverse outcome among infants at 34 weeks' gestation or less. Obstet Gynecol 98:1080-1088.

41. Yoon BH, Romero R, Moon JB, Shim SS, Kim M, et al. (2001) Clinical significance of intra-amniotic inflammation in patients with preterm labor and intact membranes. Am J Obstet Gynecol 185: 1130-1136.

42. Stillbirth Collaborative Research Network Writing Group1 (2011) Causes of death among stillbirths. JAMA 306: 2459-2468.

43. Gomez R, Romero R, Ghezzi F, Yoon BH, Mazor M, et al. (1998) The fetal inflammatory response syndrome. Am J Obstetr Gynecol 179: 194-202.

44. Wynn JL, Hansen NI, Das A, Cotton CM, Goldberg RN, et al. (2013) Early sepsis does not increase the risk of late sepsis in very low birth weight neonates. J Pediatr162: 942-948.

45. Strunk T, Doherty D, Jacques A, Simmer K, Richmond P, et al. (2012) Histologic chorioamnionitis is associated with reduced risk of late-onset sepsis in preterm infants. Pediatrics 129: 134-141.

46. Mercer BM, Miodovnik M, Thurnau GR, Goldenberg RL, Das AF, et al. (1997) Antibiotic therapy for reduction of infant morbidity after preterm premature rupture of the membranes. National Institute of Child Health and Human Development Maternal-Fetal Medicine Units Network. A randomized controlled trial. JAMA 278: 989-995.

47. Gomez R, Romero R, Nien JK, Medina L, Carstens M, et al. (2007) Antibiotic administration to patients with preterm premature rupture of membranes does not eradicate intra-amniotic infection. J Matern Fetal Neonatal Med 20: 167-173.

48. Jacquot A, Neveu D, Aujoulat F, Mercier G, Marchandin H, et al. (2011) Dynamics and clinical evolution of bacterial gut microflora in extremely premature patients. J Pediatr 158: 390-396.

49. Kuppala VS, Meinzen-Derr J, Morrow AL, Schibler KR (2011) Prolonged initial empirical antibiotic treatment is associated with adverse outcomes in premature infants. J Pediatr 159: 720-725.

50. Stoll BJ, Hansen NI, Bell EF, Shankaran S, Laptook AR, et al. (2010) Neonatal outcomes of extremely preterm infants from the NICHD Neonatal Research Network. Pediatrics 126: 443-456.

51. Brady MT, Polin RA (2013) Prevention and management of infants with suspected or proven neonatal sepsis. Pediatrics 132: 166-168. 
Citation: Conom DH, Powers RJ (2015) Revisiting the Preterm Gastric Aspirate: Potential for Use as an Additional Predictor for Chorioamnionitis, Early-Onset Sepsis, and Complications of Inflammation. J Neonatol Clin Pediatr 2: 009.

52. Verani JR, McGee L, Schrag SJ (2010) Prevention of perinatal group B streptococcal disease: Revised guidelines from CDC, 2010. MMWR Recomm Rep 59: 1-36.

53. Buck C, Bundschu J, Gallati H, Bartmann P, Pohlandt F (1994) Interleukin-6: a sensitive parameter for the early diagnosis of neonatal bacterial infection. Pediatrics 93: 54-58.

54. Romero R, Quintero R, Nores J, Avila C, Mazor M, et al. (1991) Amniotic fluid white blood cell count: a rapid and simple test to diagnose microbial invasion of the amniotic cavity and predict preterm delivery. Am J Obstet Gynecol 165: 821-830.

55. Stoll BJ, Hansen NI, Sanchez PJ, Faix RG, Poindexter BB, et al. (2011) Early onset neonatal sepsis: the burden of Group B streptococcal and $E$. coli disease continues. Pediatrics127: 817-826.

56. Pammi M, Zhong D, Johnson Y, Revell P, Versalovic J (2013) Neonatal poly microbial infections are common and contribute to increased mortality. Proceedings of the Pediatric Academic Societies Annual Meeting, Washington DC, USA.

57. Combs CA, Gravett M, Garite TJ, Hickok DE, Lapidus J, et al. (2014) Amniotic fluid infection, inflammation, and colonization in preterm labor with intact membranes. Am J Obstet Gynecol 210: 125.

58. DiGiulio DB, Romero R, Amogan HP, Kusanovic JP, Bik EM, et al. (2008) Microbial prevalence, diversity and abundance in amniotic fluid during preterm labor: a molecular and culture-based investigation. PLoS One 3: 3056.

59. Oue S, Hiroi M, Ogawa S, Hira S, Hasegawa M, et al. (2009) Association of gastric fluid microbes at birth with severe bronchopulmonary dysplasia. Arch Dis Child Fetal Neonatal Ed 94: 17-22.

60. Gibbs RS, Duff P (1991) Progress in pathogenesis and management of clinical intraamniotic infection. Am J Obstet Gynecol 164: 1317-1326.

61. Benitz WE (2010) Adjunct laboratory tests in the diagnosis of early-onset neonatal sepsis. Clin Perinatol 37: 421-438.

62. Philip AG, Hewitt JR (1980) Early diagnosis of neonatal sepsis. Pediatrics 65: 1036-1041.

63. Benitz WE, Gould JB, Druzin ML (1999) Risk factors for early-onset group B streptococcal sepsis: estimation of odds ratios by critical literature review. Pediatrics 103: 77

64. Lukacs SL, Schrag SJ (2012) Clinical sepsis in neonates and young infants, United States, 1988-2006. J Pediatr 160: 960-965.

65. Harada T, Hyman PE, Everett S, Ament ME (1984) Meal-stimulated gastric acid secretion in infants. J Pediatr 104: 534-538.

66. Ingram DL, Pendergrass EL, Bromberger PI, Thullen JD, Yoder CD, et al. (1980) Group B streptococcal disease: its diagnosis with the use of antigen detection, Gram's stain, and the presence of apnea, hypotension. Am J Dis Child 134: 754-758.

67. Christensen KK, Christensen $\mathrm{P}$, Dahlander $\mathrm{K}$, Lindén $\mathrm{V}$, Lindroth $\mathrm{M}$, et al. (1983) The significance of group B streptococci in neonatal pneumonia. Eur J Pediatr 140: 118-122.

68. El-Radhi AS, Jawad M, Mansor N, Jamil I, Ibrahim M (1983) Sepsis and hypothermia in the newborn infant: value of gastric aspirate examination. J Pediatr 103: 300-302.
69. Mims LC, Medawar MS, Perkins JR, Grubb WR (1972) Predicting neonatal infections by evaluation of the gastric aspirate: a study in two hundred and seven patients. Am J Obstet Gynecol 114: 232-238.

70. Pole JR, McAllister TA (1975) Gastric aspirate analysis in the newborn. Acta Paediatr Scand 64: 109-112.

71. Polin RA, Committee on Fetus and Newborn (2012) Management of neonates with suspected or proven early-onset bacterial sepsis. Pediatrics 129: 1006-1015

72. Jones V, Wilks M, Johnson G, Warwick S, Hennessey E, et al. (2010) The use of molecular techniques for bacterial detection in the analysis of gastric aspirates collected from infants on the first day of life. Early Hum Dev 86: 167-170.

73. Miralles R, Hodge R, McParland PC, Field DJ, Bell SC, et al. (2005) Relationship between antenatal inflammation and antenatal infection identified by detection of microbial genes by polymerase chain reaction. Pediatr Res 57: 570-577.

74. Benitz WE, Han MY, Madan A, Ramachandra P (1998) Serial serum C-reactive protein levels in the diagnosis of neonatal infection. Pediatrics 102: 41.

75. Cantey JB, Sánchez PJ (2011) Prolonged antibiotic therapy for "culture-negative" sepsis in preterm infants: it's time to stop! J Pediatr 159: 707-708.

76. Kiser C, Nawab U, Taha D, Ziegler KA, Aghai Z (2013) Chorioamnionitis and neonatal sepsis: are we treating too many infants with prolonged antibiotics? Proceedings of Pediatric Academic Societies Annual Meeting; May 4-7; Washington DC; Abstract 4511.206.

77. Sgro MD, Campbell DM, Tenuta A, Sgro A, Bertelle V, et al. (2013) Early onset sepsis and meningitis: rate and organism pattern between 2003-2011. Proceedings of Pediatric Academic Societies Annual Meeting; May 4-7; Washington DC; Abstract 4506.151.

78. Sagie G, Ergaz-Shaltiel Z, Bar-Oz B, Eventov-Friedman S (2013) Association between maternal intrapartum antibiotic prophylaxis and early-onset neonatal sepsis, the causative organisms and their resistance to antibiotics. Proceedings of Pediatric Academic Societies Annual Meeting. Washington DC, USA

79. Yao JDC, Moellering RC (2011) Antibacterial agents. In: Versalovic J, Carroll K, Funke G, Jorgensen JH, Landry ML, et al., (eds.). Manual of Clinical Microbiology. (10th edn), ASM Press, Washington DC, USA, Pg: 1043-1081.

80. Xiong X, Buekens P, Fraser WD, Beck J, Offenbacher S (2006) Periodontal disease and adverse pregnancy outcomes: a systematic review. BJOG 113: 135-143.

81. Bearfield C, Davenport ES, Sivapathasundaram V, Allaker RP (2002) Possible association between amniotic fluid micro-organism infection and microflora in the mouth. BJOG 109: 527-533.

82. Aagaard K, Ma J, Antony KM, Ganu R, Petrosino J, et al. (2014) The placenta harbors a unique microbiome. Sci Transl Med 6: 237

83. Kingsmore SF, Kennedy N, Halliday HL, Van Velkinburgh JC, Zhong S, et al. (2008) Identification of diagnostic biomarkers for infection in premature neonates. Mol Cell Proteomics 7: 1863-1875. 